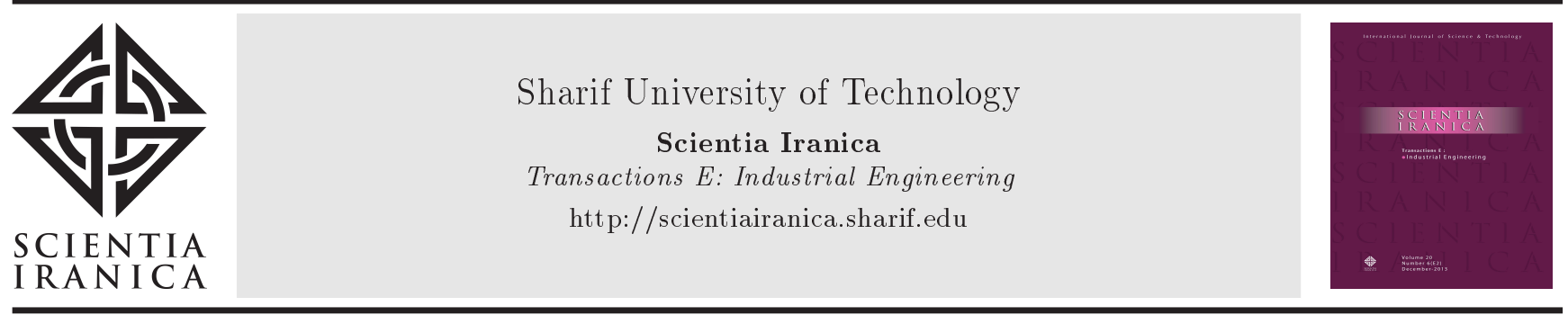

\title{
The equilibrium of venture capital incentive contract: Optimization and $Q$-learning approaches
}

\author{
S.H. Jafarpour Rezaei ${ }^{a}$ and M.A. Rastegar ${ }^{\mathrm{b}, *}$ \\ a. Faculty of Finance Sciences, Kharazmi University, Tehran, Iran. \\ b. Department of Industrial Engineering, Tarbiat Modares University, Tehran, Iran. \\ Received 6 January 2020; received in revised form 22 August 2020; accepted 18 October 2020
}

\section{KEYWORDS \\ Venture capital; \\ Agency problems; \\ Active investor; \\ Equilibrium values; \\ Bounded rationality; \\ Learning algorithms.}

\begin{abstract}
The current study presents an incentive contract model to allocate income to venture projects. In this respect, Venture Capital (VC), as one of the main sources of financing innovative projects, faces several challenges such as moral hazards, information asymmetry, and interest conflicts, often referred to as three agency problems. In addition to the identification of the factors that may affect the income of venture projects and elaboration of cost functions, this study presented an optimal incentive contract model from the perspectives of venture capitalists and entrepreneurs. In this model, a venture capitalist, as an active investor, provides entrepreneurs with managerial and training assistance. The results revealed that the higher the initial ability of the entrepreneur was, the less money the venture capitalist would pay for training. Of note, in case the venture contract was not accepted, the wealth that the contract parties would obtain would become an influential factor in the contract payment function. This model was studied considering the bounded rationality hypothesis and implemented using the $Q$-learning algorithm. In addition, the results obtained from the $Q$-learning approach were found to be reasonably convergent with the Nash equilibrium.
\end{abstract}

(C) 2022 Sharif University of Technology. All rights reserved.

\section{Introduction}

Entrepreneurial equity investments by venture capitalists, corporate venture capitalists, angel investors, and more recently, crowd funders and accelerators are the key sources of capital that contribute to fuelling innovation and development [1]. A risk finance and Venture Capital (VC) environment are essential to wealth creation revolution and rapid economic growth

\footnotetext{
*. Corresponding author. Tel.: +9821 82884387; Fax: +982188005040

E-mail addresses: hossein.r69@gmail.com (S.H. Jafarpour Rezaei); ma_rastegar@modares.ac.ir (M.A. Rastegar)
}

doi: $10.24200 /$ sci.2020.55059.4050 that can leverage innovation, promote technology, and harness knowledge-based ideas [2]. In other words, VC is an important intermediary that enables transforming the capital into innovations in a highly productive manner [3]. Among all kinds of entrepreneurial finance, VC mostly address the growth in the revenue of companies, business models, and current investors [4]. In the financial area, VC is regarded as the frontier of innovation, liberated from the regulations and precedents of traditional markets [5]. The VC market involves earlystage and, consequently, high-risk investments, whose main members are active investors [6].

In $\mathrm{VC}$ investment, capital and competence are transferred from the venture capitalist to the entrepreneurial firm at the value-adding phase, and the capital transformation is considered as the final 
ending of the investment decision phase [7]. Venture capitalists are mainly financial intermediaries who not only provide financing but also offer advice and monitoring, and they play a very active role in negotiating with suppliers, helping recruit and compensate key individuals, and providing strategic advice and access to consultants and lawyers [8]. Therefore, the management team is an important factor for VCs [9].

VCs face four generic concerns in the investment process:

1. The entrepreneur will not work hard to maximize the value after the investment is made;

2. The entrepreneur is more aware of his ability than the VC;

3. After the investment, there will be circumstances when the $\mathrm{VC}$ disagrees with the entrepreneur and $\mathrm{VC}$ will claim the right to make decisions;

4. The entrepreneur can "hold up" the VC by threatening to leave the venture when the entrepreneur's human capital is particularly valuable to the company [10].

In uncertain environments, VCs fail to exploit even available information due to two obstacles, namely information asymmetry and agency problems [5]. The agency problem arises when the principal (venture capitalist) and agent (entrepreneur) pursue two different objectives and when the principal faces difficulty understanding what the agent is actually doing [11]. Asymmetric information refers to a situation where one party to a contract has access to the relevant information that is not available to the other party. A venture capitalist needs to trade off the benefits and costs when attempting to attenuate the agency problems in the investment process [12].

Kaplan and Stromberg reviewed the conflicts of interest between an entrepreneur and a venture capitalist and identified a number of possible ways that the investor could mitigate these conflicts. They found that the investor could first engage in information collection before deciding whether to make investment in order to screen out the ex-ante unprofitable projects and bad entrepreneurs. Second, the investor could engage in information collection and monitoring once the project is under way. Third, financial contracts, i.e., allocation of the cash flow and control rights between the entrepreneur and investor, would be designed to provide incentives for the entrepreneur to behave optimally [13]. VC investments are made under conditions with potentially extreme information asymmetry and agency cost that can motivate the parties to design financial contracts [14]. The contract tends to create a mutual understanding between the parties, hence forming a basis for successful cooperation. This justifies the time spent on negotiation in the $\mathrm{VC}$ investment process [15].

Contracting and monitoring efforts can improve the portfolio performance by reducing the possible losses caused by moral hazard and adverse selection [16]. Optimal contract arrangement can overcome the revenue conflict between the venture capitalists and entrepreneurs and help them reach mutually motivating conditions [17].

Bitler et al. developed a principal-agent model in an entrepreneurial setting and tested the predictions made by the model based on unique data derived from entrepreneurial effort and wealth in privately held firms. They found that entrepreneurial ownership shares would decrease upon increase in the firm risk; the entrepreneurial effort increased with ownership and it increased firm performance [18]. Fluck et al. proposed a model to study the design of financial contracts between entrepreneurs and venture capitalists. They demonstrated that staged financing would alleviate the effort provision problem [19]. Considering the fact that both capitalists and entrepreneurs aim to maximize their own revenue, Zou and Zhou presented an optimal contract model. They also designed an optimal contract for short- and long-term VCs from the venture capitalists and entrepreneurs' perspectives [17].

The advisory, networking, and experience services provided by VCs are complemented by the entrepreneurs' technological and innovative skills. These complementary skills will in turn create a partnership that has a significant impact on the company value [20]. Gonzalez-Uribe, referring to direct evidence based on patent citations, reported that venture capitalists diffused knowledge about their existing patented innovations among the portfolio companies [21]. Helmers et al. highlighted the significant positive effect of information transmission through the interlocking boards of directors on innovation [22]. A venture capitalist can transfer valuable knowledge to an entrepreneur and facilitate innovation. He/she can also communicate the entrepreneur's innovative knowledge to other portfolio companies. In fact, venture capitalists take on a new role as knowledge intermediaries [23].

Common sense says that to grasp investment opportunities, people do not consider only economic factors; instead, they take into account psychological factors. In fact, individuals face bounded rationality in their decisions. Bounded rationality models aim to answer the question "How do people with bounded time and knowledge make decisions?" In this regard, Rodriguez-Fernandez et al. pointed out that adequate analysis of the past actions of market players improved the decision-making process of negotiators and allowed them to maximize their outcomes. They proposed a new model based on an adaptation of the $Q$ learning reinforcement learning algorithm to estimate 
the expected prices given in contracts in a specific context. They also found that the learning method could identify the best scenario for each situation since the behavior of negotiators would change depending on the negotiation environment [24].

According to the study conducted by Vergara et al. [20], the model proposed in this study took into account several issues such as the effect of the potential market value on the revenue function, constraints of effort and capability levels, and exponential growth of these features. This model was designed to allocate the proceeds from the innovative projects with the objective of reducing the conflicts of interest between the contract parties by providing sufficient incentive for them and leading them to an optimal contract. Of note, the venture capitalists, as active investors, played a key role in the success and accumulation of the project revenue by transferring experiences to entrepreneurs and training them. This model was designed from the venture capitalists and entrepreneurs' perspectives from which the parameters of optimal contract arrangement were derived separately for each case. Further, equilibrium solutions were extracted from optimal solutions to achieve a unified strategy.

Followed by this introductory section, Section 2 describes the proposed mathematical investment model from the venture capitalists and entrepreneurs' points of view and offers optimal solutions for each party. The rest of this section calculates the equilibrium answers so that the parties can reach agreement. Finally, it examines the problem from the perspective of bounded rationality using the $Q$-learning method and reports the obtained results. Section 3 presents the most relevant conclusions of this research.

\section{The proposed model}

In the VC sphere, the entrepreneur's efforts and abilities are the determinants of income function [17]. In addition, the potential market value is believed to be affecting the income functions of the $\mathrm{VC}$ as well as the concerning effort and ability; however, it is not possible to increase the level of effort and ability indefinitely. At early stages, increase in the effort and ability is observed at a higher rate; however, from the level one onwards, it takes much capital to make a small change in the level of ability or effort. Therefore, some nonlinear functions in exponential forms were taken into account, indicating the entrepreneur's effort and ability. The ability function is developed based on the desired properties in Eq. (3). Accordingly, the VC income function (venture capitalist's observable income) can be defined as:

$$
\pi(s, \theta, V)=f_{s}(x) \cdot f_{\theta}(T) \cdot V+\varepsilon,
$$

where $f_{s}(x)$ and $f_{\theta}(T)$ represent the entrepreneur's effort and ability functions, respectively. In addition, $V$ stands for the potential market value of the company that depends on the environment and market conditions of the innovative project. Finally, $\varepsilon$, as the random error of $\mathrm{VC}$ income function, follows the normal distribution: $\varepsilon \sim N\left(0, \sigma^{2}\right)$.

Realization of the entrepreneurs' innovative ideas requires their effort. In the effort function, their effort level is denoted by $x$ which takes a value in the of range of $[0, \infty)$. The effort function is regarded as a positive but descending function, i.e., $f_{s}(0)=0, f_{s}^{\prime}>0$, and $f_{s}^{\prime \prime}<0$. The effort function is defined as:

$$
f_{s}(x)=1-e^{-\emptyset x}
$$

where $\emptyset$ is a constant coefficient that indicates the degree of convexity of $f_{s}(x)$. In the discussed function, the greater the entrepreneur's effort level, the closer the effort function to 1 . Of note, in the case of infinite effort level, it takes the value of $\left(0 \leq f_{s}(x) \leq 1\right)$ [19].

It should be noted that the venture capitalists actively invest their funds in the existing plans to obtain the ability function, meaning that in addition to investment, they increase the knowledge of entrepreneurs and improve their ability level by holding training courses and providing management assistance. One of the advantages of VC companies over other methods of financing is the management and training assistance provided by venture capitalists. Hence, entrepreneur's ability to function varies with respect to the level of cost $(T)$ paid by the venture capitalist to enhance the former ability. Therefore, it can be stated that:

$$
f_{\theta}(T)=\ln (e+T) \cdot \theta_{0}, \quad T \geq 0, \quad 0<\theta_{0} \leq 1,
$$

where $\theta_{0}$ is the ability level of the entrepreneur.

As obviously observed in the defined function, if the investor (venture capitalist) does not invest in entrepreneur training, the initial ability level of the entrepreneur will not change. On the contrary, if the venture capitalist invests in entrepreneur training $(T)$, the ability level will be greater than 1 . However, learning can compensate for lack of effort; in other words, the ultimate value of the learning function can be greater than 1: $\theta_{0} \leq f_{\theta}(T)$.

Knowing the effort and ability functions, we can define the revenue function of the plan as follows:

$$
\pi(s, \theta, V)=\left(1-e^{-\emptyset x}\right) \cdot\left(\ln (T+e) \cdot \theta_{0}\right) \cdot V+\varepsilon .
$$

This function acts such that if an infinite level is attributed to the entrepreneur's effort and no money is allocated by the venture capitalist, both parties will reach the maximum value of the company. However, it is obviously costly and sometimes impossible to make infinite efforts. In this situation, the investor attempts 
to improve the entrepreneur's ability level by spending money on training in order to achieve the maximum predicted value for the company.

To ensure the effort level of the entrepreneur and maximize the venture project, both parties should work out an incentive contract where the incentive payment function to the entrepreneur is defined as follows:

$$
S(\theta, \pi)=\alpha(\theta)+\beta(\theta) \pi,
$$

where $\alpha(\theta)$ stands for the fixed component and $\beta(\theta) \pi$ the variable component of the payment [17].

Followed by the contract approval, the VC parties incur costs. The cost incurred by the entrepreneur depends on his effort and ability. The venture capitalist pays for managing, monitoring, and training. Accordingly, the cost functions of venture capitalist and entrepreneur are defined as follows:

\section{Entrepreneur:}

$$
c(\theta, x)=\frac{b \cdot e^{\mu x}}{f_{\theta}(T)}=\frac{b \cdot e^{\mu x}}{\ln (e+T) \cdot \theta_{0}} .
$$

Venture capitalist:

$$
c_{1}(r, x, T)=\frac{e^{\mu x}}{r}+T,
$$

where $e^{\mu x}$ is the effort cost with $x$ representing the effort level of entrepreneur, and $\mu$ the constant coefficient certified based on each person's characteristics.

Subsequently, the monetary income of the contract parties is described as:

Monetary income of the venture capitalist:

$$
\begin{aligned}
m_{v}= & (1-\beta(\theta))\left(\left(1-e^{-\emptyset x}\right) \cdot\left(\ln (T+e) \cdot \theta_{0}\right) \cdot V+\varepsilon\right) \\
& -\alpha(\theta)-c_{1}(e, r) .
\end{aligned}
$$

Monetary income of entrepreneur:

$$
\begin{aligned}
m_{u}= & \alpha(\theta)+\beta(\theta)\left(\left(1-e^{-\emptyset x}\right) \cdot\left(\ln (T+e) \cdot \theta_{0}\right) \cdot V+\varepsilon\right) \\
& -c(\theta, e) .
\end{aligned}
$$

In this case, the certainty equivalent wealth for the venture capitalist and entrepreneur, respectively, are given as follows:

Venture capitalist:

$$
\begin{aligned}
E\left[m_{v}\right] & -\sigma^{2} \rho_{v} \frac{(1-\beta(\theta))^{2}}{2}=-\alpha(\theta) \\
& +(1-\beta(\theta))\left(\left(1-e^{-\emptyset x}\right) \cdot\left(\ln (T+e) \cdot \theta_{0}\right) \cdot V\right) \\
& -c_{1}(e, r)-\sigma^{2} \rho_{v} \frac{(1-\beta(\theta))^{2}}{2}
\end{aligned}
$$

Entrepreneur:

$$
\begin{aligned}
E\left[m_{u}\right] & -\sigma^{2} \rho_{u} \frac{\beta(\theta)^{2}}{2}=\alpha(\theta) \\
& +\beta(\theta)\left(\left(1-e^{-\emptyset x}\right) \cdot\left(\ln (T+e) \cdot \theta_{0}\right) \cdot V\right) \\
& -c(\theta, e)-\sigma^{2} \rho_{u} \frac{\beta(\theta)^{2}}{2},
\end{aligned}
$$

where $\rho_{v}$ is the risk aversion coefficient of the venture capitalist, $\sigma^{2} \rho_{v} \frac{(1-\beta(\theta))^{2}}{2}$ the cost of his/her risk, $\rho_{u}$ the risk aversion coefficient of the entrepreneur, and $\sigma^{2} \rho_{u} \frac{\beta(\theta)^{2}}{2}$ the cost of his/her risk [17].

\subsection{Presenting the model}

This section presents a mathematical model to obtain the optimum contract addressing both venture capitalist and entrepreneur.

\subsubsection{Venture capitalist}

From the venture capitalist's perspective, the optimum investment model is presented as follows:

$$
\begin{aligned}
\max _{\alpha, \beta, x} & -\alpha(\theta)+(1-\beta(\theta)) \\
\cdot & {\left[\left(1-e^{-\emptyset x}\right) \cdot\left(\ln (e+T) \cdot \theta_{0}\right) \cdot V\right]-\left(\frac{e^{\mu x}}{r}+T\right) } \\
& -\sigma^{2} \rho_{v} \frac{(1-\beta(\theta))^{2}}{2}
\end{aligned}
$$

s.t.:

$$
\begin{gathered}
\alpha(\theta)+\beta(\theta) \cdot\left[\left(1-e^{\emptyset x}\right) \cdot\left(\ln (e+T) \cdot \theta_{0}\right) \cdot V\right] \\
-\frac{b e^{\mu x}}{\ln (e+T) \cdot \theta_{0}}-\sigma^{2} \rho_{u} \frac{\beta(\theta)^{2}}{2} \geq m \\
I C: \max _{x} \alpha(\theta)+\beta(\theta) \cdot\left[\left(1-e^{-\emptyset x}\right) \cdot\left(\ln (e+T) \cdot \theta_{0}\right) \cdot V\right] \\
-\frac{b e^{\mu x}}{\ln (e+T) \cdot \theta_{0}}-\sigma^{2} \rho_{u} \frac{\beta(\theta)^{2}}{2},
\end{gathered}
$$

where $m$ is the wealth that the entrepreneur can obtain if the venture contract is not accepted.

\subsubsection{Entrepreneur}

The optimum investment model from the entrepreneur's perspective is:

$$
\begin{aligned}
\max _{\alpha, \beta, x} \alpha & +\beta\left[\left(1-e^{-\phi x}\right) \cdot\left(\ln (e+T) \cdot \theta_{0}\right) \cdot V\right] \\
& -\frac{b e^{\mu x}}{\ln (e+T) \cdot \theta_{0}}-\sigma^{2} \rho_{u} \frac{\beta^{2}}{2}
\end{aligned}
$$

s.t.: 


$$
\begin{gathered}
-\alpha(\theta)+(1-\beta(\theta)) \cdot\left[\left(1-e^{-\emptyset x}\right) \cdot\left(\ln (e+T) \cdot \theta_{0}\right) \cdot V\right] \\
-\left(\frac{e^{\mu x}}{r}+T\right)-\sigma^{2} \rho_{v} \frac{(1-\beta(\theta))^{2}}{2} \geq q, \\
\max _{x}-\alpha(\theta)(1-\beta(\theta)) \cdot\left[\left(1-e^{-\emptyset x}\right) \cdot\left(\ln (e+T) \cdot \theta_{0}\right) \cdot V\right] \\
-\left(\frac{e^{\mu x}}{r}+T\right)-\sigma^{2} \rho_{v} \frac{(1-\beta(\theta))^{2}}{2},
\end{gathered}
$$

where $q$ is the wealth that the investor can obtain if the venture contract is not accepted.

\subsection{Optimal solution to the model}

Based on the model presented in Section 2.1, this issue falls into the category of constrained multi-objective optimization problems. To solve this model, the Karush, Kuhn, Tucker (KKT) method was employed. In addition, to implement the conditions of the KKT, the model must be written as a maximization problem and the constraints must be $(\leq 0)$. The conditions of the KKT are:

1. $\nabla f(x)=\sum_{i=1}^{m} \lambda_{i} \nabla g_{i}(x)$;

2. $\lambda_{i} g_{i}(x)=0$;

3. $g_{i}(x) \leq 0$;

4. $\lambda_{i} \geq 0$.

In the following, we will solve the model through these conditions.

\subsubsection{Venture capitalist}

To use KKT, the IC constraint given in Section 2.1.1, which is a maximization problem without constraint, should be first solved:

$$
\begin{gathered}
I C: \max _{x} \alpha(\theta)+\beta(\theta) \cdot\left[\left(1-e^{-\emptyset x}\right) \cdot\left(\ln (e+T) \cdot \theta_{0}\right) \cdot V\right] \\
-\frac{b e^{\mu x}}{\ln (e+T) \cdot \theta_{0}}-\sigma^{2} \rho_{u} \frac{\beta(\theta)^{2}}{2} .
\end{gathered}
$$

To solve $I C$, the function is derived regarding $x$ :

$$
\begin{aligned}
\frac{\partial I C}{\partial x}= & \beta \cdot\left(\ln (e+T) \cdot \theta_{0}\right) \cdot \emptyset \cdot V \cdot e^{-\emptyset x} \\
& -\frac{b \mu \cdot e^{\mu x}}{\ln (e+T) \cdot \theta_{0}}
\end{aligned}
$$

so:

$$
x=\frac{-\ln \left(\frac{b \mu}{\beta \cdot \emptyset \cdot V \cdot\left(\ln (e+T) \cdot \theta_{0}\right)^{2}}\right)}{\emptyset+\mu} .
$$

Upon solving $I C$ and obtaining the optimal value of $x$, the IC constraint is removed from the model and then, the model is rewritten in the standard form:

$$
\begin{aligned}
\max _{\alpha, \beta, x} f: & -\alpha(\theta)+(1-\beta(\theta)) \\
\cdot & {\left[\left(1-e^{-\emptyset x}\right) \cdot\left(\ln (e+T) \cdot \theta_{0}\right) \cdot V\right] } \\
& -\left(\frac{e^{\mu x}}{r}+T\right)-\sigma^{2} \rho_{v} \frac{(1-\beta(\theta))^{2}}{2}, \\
\text { s.t.: } & g_{1}: m-\alpha(\theta)-\beta(\theta)\left[\left(1-e^{\emptyset x}\right) \cdot\left(\ln (e+T) \cdot \theta_{0}\right) \cdot V\right] \\
& +\frac{b e^{\mu x}}{\ln (e+T) \cdot \theta_{0}}+\sigma^{2} \rho_{u} \frac{\beta(\theta)^{2}}{2} \leq 0 .
\end{aligned}
$$

According to the first condition of KKT:

$\nabla f(x)=\sum_{i=1}^{n} \lambda_{i} \nabla g_{i}(x)$

$\left(\frac{\partial f}{\partial \alpha}, \frac{\partial f}{\partial \beta}\right)=\lambda_{1}\left(\frac{\partial g_{1}}{\partial \alpha}, \frac{\partial g_{1}}{\partial \beta}\right)$

$\left[\begin{array}{c}\frac{\partial f}{\partial \alpha} \\ \frac{\partial f}{\partial \beta}\end{array}\right]=\left[(1-\beta) \cdot \rho_{v} \cdot \sigma^{2}-\left(1-e^{-1}\right) \cdot\left(\ln (e+T) \cdot \theta_{0}\right) \cdot V\right]$,

$\left[\begin{array}{c}\frac{\partial g_{1}}{\partial \alpha} \\ \frac{\partial g_{1}}{\partial \beta}\end{array}\right]=\left[\begin{array}{c}-1 \\ \beta \cdot \rho_{u} \cdot \sigma^{2}-\left(1-e^{-\emptyset x}\right) \cdot\left(\ln (e+T) \cdot \theta_{0}\right) \cdot V\end{array}\right]$.

Therefore, the application of the first condition of KKT leads to the following equations:

$$
\left\{\begin{array}{l}
-1=\lambda_{1}(-1) \\
(1-\beta) \cdot \rho_{v} \cdot \sigma^{2}-\left(1-e^{-\emptyset x}\right) \cdot V \cdot\left(\ln (e+T) \cdot \theta_{0}\right) \\
\left.\quad=\beta \cdot \rho_{u} \cdot \sigma^{2}-\left(1-e^{-\emptyset x}\right) \cdot V \cdot \ln (e+T) \cdot \theta_{0}\right)
\end{array}\right.
$$

As a result:

$$
\left\{\begin{array}{l}
\lambda_{1}=1 \\
\beta^{*}(\theta)=\frac{\rho_{v}}{\rho_{v}+\rho_{u}}
\end{array}\right.
$$

By substituting $\beta^{*}(\theta)$ into Eq. (19), $x^{*}$ is obtained as follows:

$$
x^{*}=\frac{-\ln \left(\frac{b \mu\left(\rho_{u}+\rho_{v}\right)}{\rho_{v} \cdot \emptyset \cdot V \cdot\left(\ln (e+T) \cdot \theta_{0}\right)^{2}}\right)}{\emptyset+\mu} .
$$

In the following, according to the second condition of KKT, we have:

$$
\begin{aligned}
& \lambda_{i} g_{i}(x)=0, \\
& \lambda_{1}\left(m-\alpha(\theta)-\beta(\theta) \cdot\left[\left(1-e^{\emptyset x}\right) \cdot\left(\ln (e+T) \cdot \theta_{0}\right) \cdot V\right]\right. \\
& \left.\quad+\frac{b e^{\mu x}}{\ln (e+T) \cdot \theta_{0}}+\sigma^{2} \rho_{u} \frac{\beta(\theta)^{2}}{2}\right)=0,
\end{aligned}
$$


Table 1. Optimum values of decision-making variables from the perspective of the venture capitalist.

$$
\begin{aligned}
& \beta_{v}^{*}(\theta)=\frac{\rho_{v}}{\rho_{v}+\rho_{u}} . \\
& x_{v}^{*}=\frac{-\ln \left[\frac{\beta^{*} \cdot \emptyset \cdot V \cdot\left(\ln (e+T) \cdot \theta_{0}\right)^{2}}{\beta_{v}^{*}}\right.}{\emptyset+\mu} . \\
& \alpha_{v}^{*}=m+\frac{b e^{\mu x_{v}^{*}}}{\ln (e+T) \cdot \theta_{0}}+\frac{\rho_{u} \cdot \beta_{v}^{* 2} \cdot \sigma^{2}}{2}-\beta_{v}^{*} \cdot\left(1-e^{-\emptyset x_{v}^{*}}\right) \cdot V \cdot\left(\ln (e+T) \cdot \theta_{0}\right)
\end{aligned}
$$

Note: $\beta_{v}^{*}, x_{v}^{*}$, and $\alpha_{v}^{*}$ are optimum values from the venture capitalist's perspective.

Table 2. Optimum values of decision-making variables from the perspective of the entrepreneur.

$$
\begin{aligned}
\beta_{u}^{*} & =\frac{\rho_{v}}{\rho_{v}+\rho_{u}} \\
x_{u}^{*} & =\frac{-\ln \left[\frac{\mu}{\left(1-\beta_{u}^{*}\right) \cdot \emptyset \cdot r \cdot\left(\ln (e+T) \cdot \theta_{0}\right) V}\right]}{\emptyset+\mu} \\
\alpha_{u}^{*} & =\left(1-\beta_{u}^{*}\right) \cdot\left(1-e^{-\emptyset x_{u}^{*}}\right) \cdot\left(\ln (e+T) \cdot \theta_{0}\right) \cdot V-T-\frac{e^{\mu x_{u}^{*}}}{r}-\frac{\left(1-\beta_{u}^{*}\right)^{2} \cdot \rho_{v} \cdot \sigma^{2}}{2}-q
\end{aligned}
$$

Note: $\beta_{u}^{*}, x_{u}^{*}$, and $\alpha_{u}^{*}$ are optimum values from the entrepreneur's perspective.

so:

$$
\begin{aligned}
\alpha^{*}= & m+\frac{b e^{\mu x^{*}}}{\ln (e+T) \cdot \theta_{0}}+\frac{\rho_{u} \cdot \beta^{* 2} \cdot \sigma^{2}}{2} \\
& -\beta^{*} \cdot\left(1-e^{-\emptyset x^{*}}\right) \cdot V \cdot\left(\ln (e+T) \cdot \theta_{0}\right) .
\end{aligned}
$$

The third and fourth conditions of KKT based on $g_{i}(x) \leq 0$ and $\lambda_{i} \geq 0$ are also established.

Finally, we came up with the following optimal solutions for venture capitalist that are listed in Table 1.

\subsubsection{Entrepreneur}

As described in the previous section, the model proposed in Subsection 2.1.2 is solved from the entrepreneur's point of view and the obtained optimal values are listed in Table 2 .

\subsection{Equilibrium in the optimal solutions of VC parties}

A comparison of the optimal results obtained for the contract parties of the $\mathrm{VC}$ reveals that the optimum values of the effort level $(x)$ and constant component of the contract $(\alpha)$ are different for the parties. In this situation, the parties will agree if their optimum answers are close.

The equilibrium values of the parties are obtained in this section and listed in Tables 1 and 2 . An important question may arise here: how much does the venture capitalist pay $(T)$ for training the entrepreneur and increasing his/her ability to equalize the effort level of the contracting parties? In addition, in the case of non-participation in the plan $(m+q)$, how much should the total amount of income of the parties be for the constant component of the contract to make an equilibrium between the parties?

\subsubsection{Parametric equilibrium values}

In order to obtain the parametric equilibrium solution, the optimal values of the effort level, from both parties' perspective, as well as the optimal values of the constant component of the contract must be equalized. To equalize the optimal effort level of the parties, first, it should be determined that how much the capitalist should pay to train the entrepreneur in order to balance the optimal efforts level of the parties. Consequently:

$$
\begin{aligned}
& x_{v}^{*}=x_{u}^{*}, \\
& \frac{-\ln \left[\frac{b \mu}{\beta_{v}^{*} \cdot \emptyset \cdot V \cdot\left(\ln (e+T) \cdot \theta_{0}\right)^{2}}\right]}{\emptyset+\mu} \\
& =\frac{-\ln \left[\frac{\mu}{\left(1-\beta_{u}^{*}\right) \cdot \emptyset \cdot r \cdot\left(\ln (e+T) \cdot \theta_{0}\right) \cdot V}\right]}{\emptyset+\mu}, \\
& \frac{\beta_{v}^{*} \cdot \emptyset \cdot V \cdot\left(\ln (e+T) \cdot \theta_{0}\right)^{2}}{\mu} \\
& =\frac{b \mu}{\left(1-\beta_{u}^{*}\right) \cdot \emptyset \cdot r \cdot\left(\ln (e+T) \cdot \theta_{0}\right) \cdot V} .
\end{aligned}
$$

By solving the above equation, we will have:

$$
\ln (e+T)=\frac{b \cdot(1-\beta) \cdot r}{\theta_{0} \cdot \beta} .
$$

Then:

$$
T=e^{\frac{b \cdot(1-\beta) \cdot r}{\theta_{0} \cdot \beta}}-e .
$$

In the next step, the optimal answers of the constant component of the parties $(\alpha)$ should be equalized. Doing so, if the parties do not contribute to the plan, indicates how much the total income of the parties should be in order to accept the contract. Therefore, we have: 


$$
\begin{aligned}
\alpha_{v}^{*}= & \alpha_{u}^{*}, \\
m+ & \frac{b e^{\mu x_{v}^{*}}}{\ln (e+T) \cdot \theta_{0}}+\frac{\rho_{u} \cdot \beta_{v}^{*^{2}} \cdot \sigma^{2}}{2} \\
& -\beta_{v}^{*} \cdot\left(1-e^{-\emptyset x_{v}^{*}}\right) \cdot V \cdot\left(\ln (e+T) \cdot \theta_{0}\right) \\
= & \left(1-\beta_{u}^{*}\right) \cdot\left(1-e^{-\emptyset x_{u}^{*}}\right) \cdot\left(\ln (e+T) \cdot \theta_{0}\right) \cdot V \\
& -T-\frac{e^{\mu x_{u}^{*}}}{r}-\frac{\left(1-\beta_{u}^{*}\right)^{2} \cdot \rho_{v} \cdot \sigma^{2}}{2}-q .
\end{aligned}
$$

Then:

$$
\begin{gathered}
m+q=\left(1-\beta_{u}^{*}\right) \cdot\left(1-e^{-\emptyset x_{u}^{*}}\right) \cdot\left(\ln (e+T) \cdot \theta_{0}\right) \cdot V \\
-T-\frac{e^{\mu x_{u}^{*}}}{r}-\frac{\left(1-\beta_{u}^{*}\right)^{2} \cdot \rho_{v} \cdot \sigma^{2}}{2}-\frac{b e^{\mu x_{v}^{*}}}{\ln (e+T) \cdot \theta_{0}} \\
-\frac{\rho_{u} \cdot \beta_{v}^{* 2} \cdot \sigma^{2}}{2}+\beta_{v}^{*} \cdot\left(1-e^{-\emptyset x_{v}^{*}}\right) \cdot V \cdot\left(\ln (e+T) \cdot \theta_{0}\right) \cdot V .
\end{gathered}
$$

\subsubsection{Stating numeric values}

Once tending to fund through the $\mathrm{VC}$, entrepreneurs must present their innovative plan(s) to the venture capitalist for assessment and examination. The capitalist's assessment illustrates that the entrepreneur's innovative plan, if successful, could bring a value of 15 units $(V=15)$ for the venture company. Moreover, the entrepreneur's proposed plan was estimated to be 0.4 at the total investment required in the plan $(r=0.4)$. The entrepreneur's initial ability level was placed at the closed interval of $[0,1]$ (in this study, it was $\left(\theta_{0}=1\right.$ ); however, it can vary while the capitalist holds training courses). The standard deviation, as a measurement of risk aversion, equals $1(\sigma=1)$. In all studies, the entrepreneur was considered to be more risk averse than the venture capitalist. Therefore, in this study, it is assumed that entrepreneur's and venture capitalist's risk aversion coefficients are 3 and 1 , respectively $\left(\rho_{u}=\right.$ $\left.3, \rho_{v}=1\right)$. There are also constant coefficients in the functions allocated to effort and cost which are used to determine the degree of convexity and gradient of the functions. In this numerical study, according to the personal characteristics of the entrepreneur and capitalist, the following values are estimated for these coefficients:

$$
\mu=0.2, \quad \emptyset=0.2, \quad b=1 .
$$

\subsubsection{Solving a numerical example and finding the equilibrium values}

To find the optimal values, the aforementioned numbers are put into the optimal numbers as shown below:

$$
\beta_{v}^{*}=\beta_{u}^{*}=\frac{1}{4}=0.25 .
$$

Now, we are looking for an optimal value for $T$ to create equilibrium at the effort level of the parties. Upon inserting the above values in Eq. (27), we will have:

$$
\begin{aligned}
& T=e^{\frac{1 * 0.75 * 0.4}{1 * 0.25}}-e, \\
& T=e^{1.2}-e=0.6018 .
\end{aligned}
$$

Finally, once the optimal value for $T$ is determined, the optimal and equilibrium values of the effort level, from the perspective of the contract parties, are as follows:

$$
x_{v}^{*}=x_{u}^{*}=4.216 .
$$

By determining the equilibrium values of $\beta$ and $x$ as well as the desired cost of holding the training courses $(T)$, we can create equilibrium in the values of the constant component of the contract $(\alpha)$.

By substituting the numbers into Eq. (28), the following result will be obtained:

$$
m+q=1.5313 \text {. }
$$

Therefore, if the total saved capital of the capitalist and entrepreneur (if not participating in the plan) is 1.5313 units, equilibrium in the constant component of the contract will be reached.

Ultimately, with regard to the assumptions of the problem and values defined for the variables, the optimal values from the parties' perspectives are summarized in Table 3 . Of note, the optimal values given in Table 3 were calculated, assuming that $T=0.6018$.

As shown, $\alpha$, income, and profit are sensitive to $m$ and $q$. The effects of $m$ and $q$ values on $\alpha$ and profit are illustrated in Figures 1 and 2, respectively.

\subsection{Bounded rationality vs. game theory}

Here, the venture capitalist and entrepreneur, as the two parties in the contract, are consequently considered as parties to the game, facing numerous strategic decisions to cooperate with each other. Given the nature of the model and variables used in it, the values of $\alpha$

Table 3. Optimal values of numerical example from the perspective of the parties.

\begin{tabular}{lccccc}
\hline & $\boldsymbol{\beta}$ & $\boldsymbol{x}(\boldsymbol{T}=\mathbf{0 . 6 0 1 8})$ & $\boldsymbol{\alpha}$ & Income & Profit \\
\hline Venture capitalist & 0.25 & 4.216 & $m-0.5333$ & 7.6905 & $1.5313-m$ \\
Entrepreneur & 0.25 & 4.216 & $0.9980-q$ & $3.5615-q$ & $1.5313-q$ \\
\hline
\end{tabular}




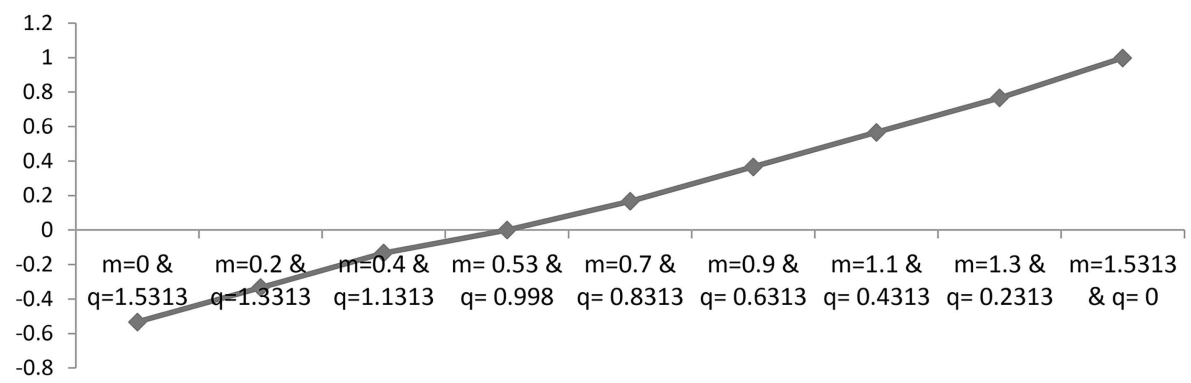

Figure 1. $\alpha$ sensitivity analysis relative to $m$ and $q$.

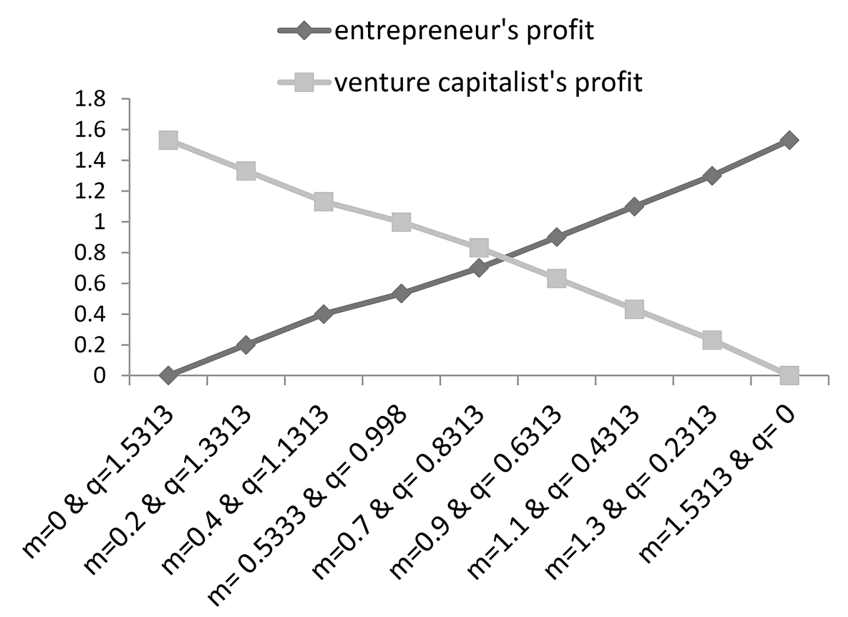

Figure 2. Profit sensitivity analysis relative to $m$ and $q$.

and $x$ are assumed to be the entrepreneur's strategies and the values of $\beta$ and $T$ are the investor's strategies. As a result, five-by-five matrices of possible strategies of each party involved in the investment can be made, and their earnings are calculated. The logic behind this is that if the investor proposes a low $\beta$, a higher cost will be allocated to training the entrepreneur since the proposed $\beta$ is proportional to the ability of the entrepreneur, and choosing a low $\beta$ indicates that the investor believes in the entrepreneur's low ability, hence forced to provide more educational services.

On the contrary, there are two views concerning the entrepreneur:

1. Entrepreneurs increase their effort with the increase in the proposed $\alpha$ (Table 4 ),

2. Entrepreneurs decrease their effort with the increase in the proposed $\alpha$ (Table 5).

In this matrix, the entrepreneur's and venture capitalist's strategies are shown in the first row and column, respectively. The values written in the matrix represent the players' income where the upper value is related to the venture capitalist and the lower value belongs to the entrepreneur. In each of the matrix cells, the numbers on the left correspond to the individuals' profit, while those on the right (the larger number) correspond to their income regardless of the costs.

Table 4. Strategies matrix of entrepreneur and investor based on different strategic decisions (the first view of the entrepreneur).

\begin{tabular}{|c|c|c|c|c|c|c|}
\hline & \multicolumn{5}{|c|}{ Entrepreneur } \\
\hline & & $\alpha=0.1$ & $\alpha=0.2$ & $\alpha=0.3$ & $\alpha=0.4$ & $\alpha=0.46$ \\
\hline & & $x=4.2$ & $x=4.7$ & $x=5.2$ & $x=5.7$ & $x=6$ \\
\hline \multirow{10}{*}{$\begin{array}{l}\dot{0} \\
\dot{d} \\
0 \\
0 \\
\vec{\Xi}\end{array}$} & $\beta=0.1$ & $2.6134,9.7593$ & $2.6099,10.4648$ & $2.4752,11.1032$ & $2.2089,11.6808$ & $1.9854,12.0007$ \\
\hline & $T=0.85$ & $0.6516,1.1844$ & $-0.6647,1.3628$ & $-0.7054,1.5337$ & $-0.7751,1.6979$ & $-0.8316,1.7934$ \\
\hline & $\beta=0.17$ & $1.7823,8.7377$ & $1.7049,9.3693$ & $1.5034,9.9409$ & $1.1767,10.4581$ & $0.9197,10.7444$ \\
\hline & $T=0.72$ & $-0.0293,1.8896$ & $0.0028,2.1190$ & $0.0018,2.3361$ & $-0.0332,2.5420$ & $-0.0711,2.6607$ \\
\hline & $\beta=0.25$ & $0.8962,7.6684$ & $0.7415,8.2227$ & $0.47,8.7243$ & $0.08,9.1782$ & $-0.212,9.4295$ \\
\hline & $T=0.6$ & $0.6312,2.6561$ & $0.7129,2.9409$ & $0.7556,3.2081$ & $0.7588,3.4594$ & $0.7414,3.6032$ \\
\hline & $\beta=0.32$ & $0.137,6.7392$ & $-0.0848,7.2263$ & $-0.4171,7.6672$ & $-0.8621,8.066$ & $-1.1846,8.2869$ \\
\hline & $T=0.48$ & $1.1254,3.2714$ & $1.2451,3.6006$ & $1.321,3.9081$ & $1.3528,4.1958$ & $1.3504,4.3597$ \\
\hline & $\beta=0.4$ & $-0.6868,5.7341$ & $-0.9814,6.1486$ & $-1.3794,6.5237$ & $-1.8839,6.8631$ & $-2.2393,7.0510$ \\
\hline & $T=0.35$ & $1.6166,3.9227$ & $1.7756,4.2991$ & $1.8856,4.6491$ & $1.9464,4.9754$ & $1.9592,5.1607$ \\
\hline
\end{tabular}

Source: Research calculations. 
Table 5. Strategies matrix of entrepreneur and investor based on different strategic decisions (the second view of the entrepreneur).

\begin{tabular}{|c|c|c|c|c|c|c|}
\hline & \multicolumn{5}{|c|}{ Entrepreneur } \\
\hline & & $\alpha=0.1$ & $\alpha=0.2$ & $\alpha=0.3$ & $\alpha=0.4$ & $\alpha=0.46$ \\
\hline & & $x=4.2$ & $x=3.7$ & $x=3.2$ & $x=2.7$ & $x=2.4$ \\
\hline \multirow{10}{*}{ 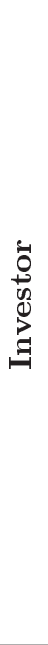 } & $\beta=0.1$ & $2.6134,9.7593$ & $2.2848,8.9796$ & $1.8217,8.1179$ & $1.2205,7.1655$ & $0.7915,6.5467$ \\
\hline & $T=0.85$ & $0.6516,1.1844$ & $-0.4649,1.1977$ & $-0.3039,1.202$ & $-0.1678,1.1962$ & $-0.098,1.1874$ \\
\hline & $\beta=0.17$ & $1.7823,8.7377$ & $1.5353,8.0396$ & $1.1624,7.2681$ & $0.6609,6.4154$ & $0.2967,5.8614$ \\
\hline & $T=0.72$ & $-0.0293,1.8896$ & $0.1062,1.8467$ & $0.2096,1.7886$ & $0.2811,1.714$ & $0.3086,1.6605$ \\
\hline & $\beta=0.25$ & $0.8962,7.6684$ & $0.7346,7.0557$ & $0.4562,6.3786$ & $0.059,5.6303$ & $-0.2374,5.1441$ \\
\hline & $T=0.6$ & $0.6312,2.6561$ & $0.7107,2.5519$ & $0.7513,2.4262$ & $0.7524,2.2768$ & $0.7336,2.1747$ \\
\hline & $\beta=0.32$ & $0.137,6.7392$ & $0.0497,6.2007$ & $-0.1467,5.6057$ & $-0.4532,4.948$ & $-0.6907,4.5207$ \\
\hline & $T=0.48$ & $1.1254,3.2714$ & $1.1616,3.118$ & $1.1531,2.9380$ & $1.0989,2.7285$ & $1.0438,2.5874$ \\
\hline & $\beta=0.4$ & $-0.6868,5.7341$ & $-0.6939,5.276$ & $-0.8016,4.7696$ & $-1.0099,4.2101$ & $-1.1837,3.8465$ \\
\hline & $T=0.35$ & $1.6166,3.9227$ & $1.6078,3.7173$ & $1.5482,3.4798$ & $1.4361,3.2067$ & $1.3428,3.0243$ \\
\hline
\end{tabular}

Source: Research calculations

Individuals' incomes and benefits are calculated based on the items such as the cost of risk-taking in the cost section as well as the non-real and tangible costs in order to clarify the results.

To meet the conditions of bounded rationality in the model, assume that in the initial stage, the contract parties with bounded knowledge and incomplete recognition of each other will make one of the strategic decisions. With additional information and a greater understanding of the environment over time, the parties will update their strategies. As a result, learning will happen during the implementation of the contract and will affect the decisions of individuals. Therefore, learning algorithms are used in the model. This study also employed $Q$-learning algorithm as one of the reinforcement learning algorithms.

In this learning algorithm, the player number $i$ performs the activity $a_{t}^{i}$ at moment $t$ and receives the reward $R_{t}^{i}\left(a_{t}^{i}, a_{t}^{-i}\right)$ based on the activity $a_{t}^{-i}$, which is played by the rival. Then, function $Q$ is updated based on the following recursive formula:

$Q_{t+1}^{i}\left(a^{i}\right)=\left\{\begin{array}{lr}\left(1-\alpha_{t}\right) Q_{t}^{i}\left(a^{t}\right) & \\ +\alpha_{t}\left[R_{t}^{i}+\gamma \max _{a^{\prime}} Q_{t}^{i}\left(a^{\prime}\right)\right] ; & \text { if } a^{i}=a_{t}^{i}, \\ Q_{t}^{i}\left(a^{i}\right) ; & \text { otherwise }\end{array}\right.$

where $\gamma$ is the reducing factor and $\alpha_{t}=C_{t-1}^{i}\left(a^{i}\right)^{-\delta}$ the learning rate variable. Then, the next activity, $a_{t+1}^{i}$, is randomly chosen from the probabilities determined through the following exponential decision-making formula:

$$
\pi_{t}^{i}\left(a^{i}\right)=\frac{e^{\lambda_{t} Q_{t}^{i}\left(a^{i}\right)}}{\sum_{a^{i}} e^{\lambda_{t} Q_{t}^{i}\left(a^{i}\right)}} .
$$

The results of this algorithm depend on many factors including the parameters used in the model such as $\gamma, \delta$, and $\lambda$ that have a great impact on the results. Other factors are the frequency of learning the model and its run time. In this regard, numerous studies have been carried out to find proper values for these parameters. The values $\gamma=0.96, \delta=0.63$, and $\lambda=6$ were taken into account in this study [25]. Among the most important and influential factors are the condition of stopping the algorithm (the degree of probability convergence of the chosen strategy) and random choices in the algorithm. This study took into account the probability of higher than 0.999 for the players simultaneously. On the other hand, random choices of the algorithm made the software output results not the same. To solve this problem, the algorithm should be repeated until learning takes place. In doing so, the probability of choosing each matrix cell and each strategy by the parties can be determined. The results of the two previously presented games are given in Tables 6 and 7 . In the given matrix, the upper and lower numbers in each cell represent the number of repetitions and the corresponding probability, respectively.

The created matrices can be examined based on game theory. This game has two players who decide at the same time. Here, each player must maximize his/her expected income based on his/her perceptions of the other player. Based on interpretations, Nash 
Table 6. The number of repetitions and the probability of choosing each matrix cell (the first view of the entrepreneur).

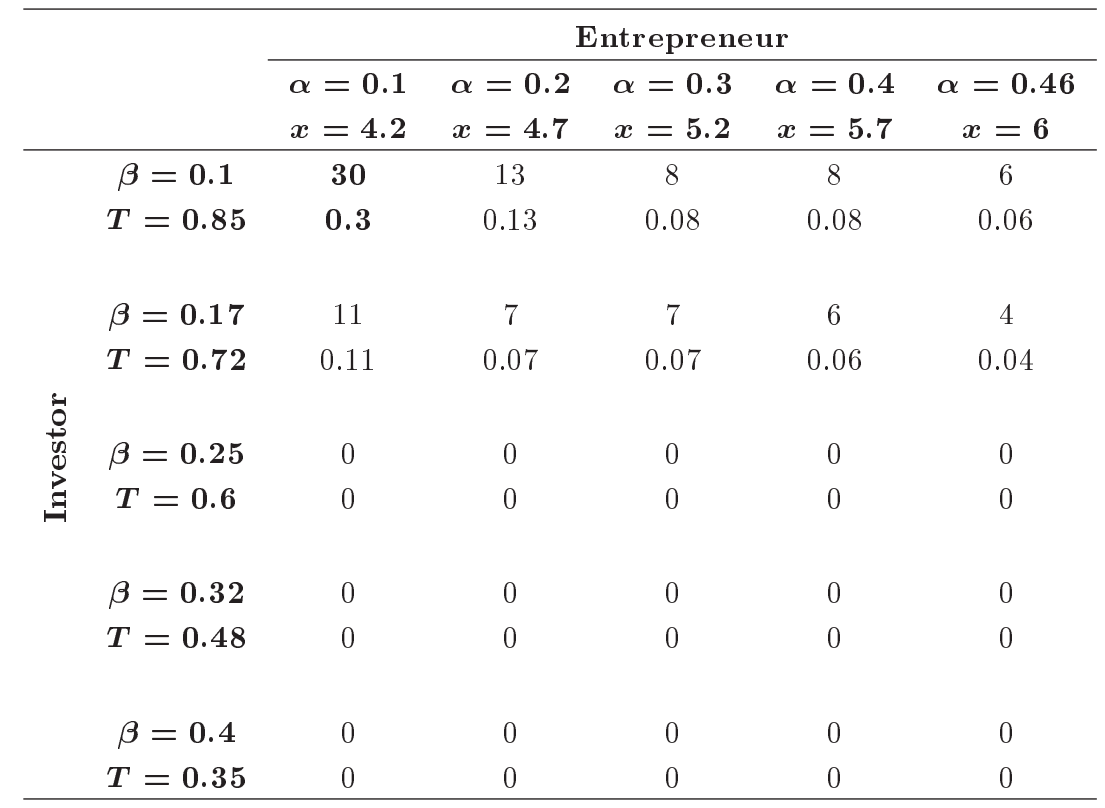

Table 7. The number of repetitions and the probability of choosing each matrix cell (the second view of the entrepreneur).

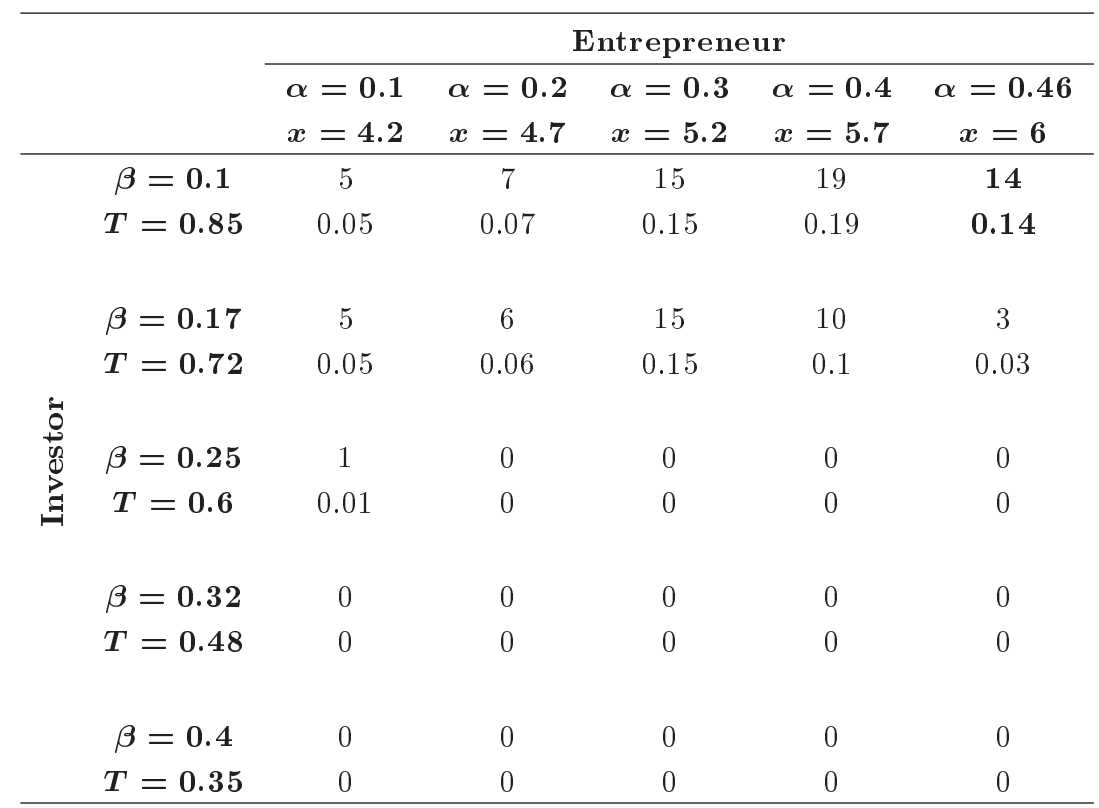

equilibrium in the generated game matrices can be calculated. The most important feature of the Nash equilibrium is that the outcome is not the greatest for the players. In this balance, the assumption of the rationality of the players is a necessary condition, and the correctness of each player's belief in choosing the opponent is a sufficient condition. The distinct cell in Tables 6 and 7 indicates the Nash equilibrium.

Tables 8 and 9 show the probability of choosing each strategy for the investment parties based on the first and second views of the entrepreneurs.

The basis of the calculations is the profit earned so that the results can be compared with those of the mathematical solution.

\section{Conclusion}

This paper attempted to design a model for venture capital contracts to prove that despite different expectations of the contract parties, equilibrium points exist that could convince the parties to sign the contract.

As mentioned earlier, the optimal values of the models from the perspectives of each party varied, thus making it impossible to achieve a single strategy 
Table 8. The probability of choosing each party's strategic decisions based on the first view of entrepreneur.

\begin{tabular}{lccccc}
\hline \multirow{4}{*}{ Investor } & $\boldsymbol{\beta}=\mathbf{0 . 1}$, & $\boldsymbol{\beta}=\mathbf{0 . 1 7}$, & $\boldsymbol{\beta}=\mathbf{0 . 2 5}$, & $\boldsymbol{\beta}=\mathbf{0 . 3 2}$, & $\boldsymbol{\beta}=\mathbf{0 . 4}$, \\
& $\boldsymbol{T}=\mathbf{0 . 8 5}$ & $\boldsymbol{T}=\mathbf{0 . 7 2}$ & $\boldsymbol{T}=\mathbf{0 . 6}$ & $\boldsymbol{T}=\mathbf{0 . 4 8}$ & $\boldsymbol{T}=\mathbf{0 . 3 5}$ \\
\cline { 2 - 6 } & 0.65 & 0.35 & 0 & 0 & 0 \\
\hline \multirow{3}{*}{ Entrepreneur } & $\boldsymbol{\alpha}=\mathbf{0 . 1}$, & $\boldsymbol{\alpha}=\mathbf{0 . 2}$, & $\boldsymbol{\alpha}=\mathbf{0 . 3}$, & $\boldsymbol{\alpha}=\mathbf{0 . 4}$, & $\boldsymbol{\alpha}=\mathbf{0 . 4 6}$, \\
& $\boldsymbol{x}=\mathbf{4 . 2}$ & $\boldsymbol{x}=\mathbf{3 . 7}$ & $\boldsymbol{x}=\mathbf{3 . 2}$ & $\boldsymbol{x}=\mathbf{2 . 7}$ & $\boldsymbol{x}=\mathbf{2 . 4}$ \\
\cline { 2 - 6 } & 0.44 & 0.2 & 0.15 & 0.14 & 0.1 \\
\hline
\end{tabular}

Table 9. The probability of choosing each party's strategic decisions based on the second view of entrepreneur.

\begin{tabular}{lccccc}
\hline \multirow{4}{*}{ Investor } & $\boldsymbol{\beta}=\mathbf{0 . 1}$, & $\boldsymbol{\beta}=\mathbf{0 . 1 7}$, & $\boldsymbol{\beta}=\mathbf{0 . 2 5}$, & $\boldsymbol{\beta}=\mathbf{0 . 3 2}$, & $\boldsymbol{\beta}=\mathbf{0 . 4}$, \\
& $\boldsymbol{T}=\mathbf{0 . 8 5}$ & $\boldsymbol{T}=\mathbf{0 . 7 2}$ & $\boldsymbol{T}=\mathbf{0 . 6}$ & $\boldsymbol{T}=\mathbf{0 . 4 8}$ & $\boldsymbol{T}=\mathbf{0 . 3 5}$ \\
\cline { 2 - 6 } & 0.60 & 0.39 & 0.01 & 0 & 0 \\
\hline \multirow{3}{*}{ Entrepreneur } & $\boldsymbol{\alpha}=\mathbf{0 . 1}$, & $\boldsymbol{\alpha}=\mathbf{0 . 2}$, & $\boldsymbol{\alpha}=\mathbf{0 . 3}$, & $\boldsymbol{\alpha}=\mathbf{0 . 4}$, & $\boldsymbol{\alpha}=\mathbf{0 . 4 6 ,}$ \\
\cline { 2 - 6 } & $\boldsymbol{x}=\mathbf{4 . 2}$ & $\boldsymbol{x}=\mathbf{4 . 7}$ & $\boldsymbol{x}=\mathbf{5 . 2}$ & $\boldsymbol{x}=\mathbf{5 . 7}$ & $\boldsymbol{x}=\mathbf{6}$ \\
\hline
\end{tabular}

and sign a contract in the real world. To find the equilibrium values and sign the contract, the optimal values of the effort level $(x)$ and fixed component of the incentive payment function $(\alpha)$ from the perspective of each party should be equalized. Then, the values of $T$ (the cost of entrepreneur training) and $m+q$ (the total wealth that both parties to the contract could obtain if the contract was not accepted) were determined.

According to our expectations, the higher the initial ability of the entrepreneur is, the less money the venture capitalists will pay for their training. In addition, the higher the value of $q$ is, the lower the value of $\alpha$ (fixed component of the entrepreneur's payment function) will be suggested by the venture capitalist; in addition, the higher the value of $m$ is, the greater the value the entrepreneur will call for $\alpha$; the results confirm these expectations.

As is clear, both entrepreneurs and venture capitalists seek to optimize the model from their own perspectives. This study shows that if the values of $T$ (the cost of entrepreneur training) and $m+q$ (total wealth that the parties to the contract can obtain if the contract is not accepted) are close to the equilibrium points obtained in the models, the optimal values of decision variables in the models of each party will be equal. In addition, as the distance from the equilibrium values increases, the probability of concluding a contract is reduced because of the conflict of interest.

In the learning algorithms section, the computational results of the $Q$-learning algorithm indicate that learning has been completely done for the investors because they only choose the strategies that generate the highest income in the first and second rounds, but learning has not been well done for the entrepreneurs; thus, they select all of their strategies with different possibilities (higher than 10\%). In the second scenario, the investors also learn very well and are more likely to choose profitable strategies. Finally, learning happens for the entrepreneurs and they select the profitable strategies with higher probabilities.

According to Table 6, in the first scenario, the first matrix cell is introduced as the Nash equilibrium. Based on Table 6, which shows the results of 100 iterations of the $Q$-learning algorithm, we find that the parties most likely choose the Nash equilibrium point. That is, Q-learning outcomes converge with Nash equilibrium results. Also, according to Table 7, in the second scenario, the cell ${ }_{1 * 5}$ is selected as the Nash equilibrium. This cell would be most likely selected by the parties compared to other cells. Therefore, the results of the $Q$-learning are reasonably convergent with Nash equilibrium.

\section{References}

1. Drover, W., Busenitz, L., Matusik, S., et al. "A review and road map of entrepreneurial equity financing research: venture capital, corporate venture capital, angel investment, crowdfunding, and accelerators", Journal of Management, 43(6), pp. 1820-1853 (2017).

2. Selvakumar, M. and Ketharaj, M. "Venture capital for startups", Facts for You, 29(5), pp. 29-32 (2009).

3. Kaplan, S.N. and Lerner, J. "Venture capital data: Opportunities and challenges", National Bureau of Economic Research (2016).

4. Block, J., Fisch, C., Vismara, S., et al. "Private equity investment criteria: An experimental conjoint analysis of venture capital, business angels, and family offices", Journal of Corporate Finance, 58, pp. 329-352 (2019).

5. Triantis, G.G. "Financial contract design in the world of venture capital (reviewing the venture capital cycle 
by Paul Gompers, Josh Lerner", University of Chicago Law Review, 68(1), p. 8 (2001).

6. Burchardt, J., Hommel, U., Kamuriwo, D.S., et al. "Venture capital contracting in theory and practice: implications for entrepreneurship research", Entrepreneurship Theory and Practice, 40(1), pp. 25-48 (2016).

7. Smith, R.L. and Smith, J.K., Entrepreneurial Finance, John Wiley, New York (2000).

8. Dessi, R. "Start-up finance, monitoring, and collusion", RAND Journal of Economics, 36(2), pp. 255274 (2005).

9. Gompers, P., Kaplan, S.N., and Mukharlyamov, V. "What do private equity firms say they do?", Journal of Financial Economics, 121(3), pp. 449-476 (2016).

10. Kaplan, S.N. and Strömberg, P.E. "Characteristics, contracts, and actions: Evidence from venture capitalist analyses", The Journal of Finance, 59(5), pp. 2177-2210 (2004).

11. Gabrielsson, J. and Huse, M. "The venture capitalist and the board of directors in SMEs: roles and processes", Venture Capital: An International Journal of Entrepreneurial Finance, 4(2), pp. 125-146 (2002).

12. Bellavitis, C., Kamuriwo, D.S., and Hommel, U. "Mitigation of moral hazard and adverse selection in venture capital financing: the influence of the country's institutional setting", Journal of Small Business Management, 57(4), pp. 1328-1349 (2019). https://doi.org/10.1111/jsbm.12391

13. Kaplan, S.N. and Strömberg, P.E. "How do venture capitalists choose investments", University of Chicago Working Paper, 121, pp. 55-93 (2000).

14. Klausner, M. and Litvak, K. "What economists have taught us about venture capital contracting", In Bridging the Entrepreneurial Financing Gap, Routledge, London, pp. 54-74 (2017).

15. Pathak, B. "Study on venture capital industry in India with special reference to Gujarat" (2010).

16. Berg-Utby, T., SøRheim, R., and Widding, L. $\varnothing$. "Venture capital funds: Do they meet the expectations of portfolio firms?", Venture Capital, 9(1), pp. 23-41 (2007).

17. Zou, H. and Zhou, X. "The design of the incentive contract of venture capital under asymmetric information", In 2011 Fourth International Conference on Business Intelligence and Financial Engineering, IEEE, pp. 475-479 (2011).
18. Bitler, M.P., Moskowitz, T.J., and Vissing-Jørgensen, A. "Testing agency theory with entrepreneur effort and wealth", The Journal of Finance, 60(2), pp. 539-576 (2005).

19. Fluck, Z., Garrison, K., and Myers, S.C. "Venture capital contracting: Staged financing and syndication of later-stage investments", NBER Working Paper (2006).

20. Vergara, M., Bonilla, C.A., and Sepulveda, J.P. "The complementarity effect: Effort and sharing in the entrepreneur and venture capital contract", European Journal of Operational Research, 254(3), pp. 10171025 (2016).

21. Gonzalez-Uribe, J. "Venture capital and the diffusion of knowledge", Available at SSRN 2405362 (2014).

22. Helmers, C., Patnam, M., and Rau, P.R. "Do board interlocks increase innovation? Evidence from natural experiments in India", University of Cambridge Working Paper (2013).

23. Dessi, R. and Yin, N. "Venture capital and knowledge transfer", Toulouse School of Economics (TSE) Working Papers, Available at SSRN 2642596 (2015).

24. Rodriguez-Fernandez, J., Pinto, T., Silva, F., and et al. "Context aware q-learning-based model for decision support in the negotiation of energy contracts", International Journal of Electrical Power \& Energy Systems, 104, pp. 489-501 (2019).

25. Guerci, E. and Rastegar, M.A. "The role of information in multi-agent learning", Document de Travail, $\mathbf{4 7}$ (2009).

\section{Biographies}

Seyed Hossein Jafarpour Rezaei is an MSc graduate student from School of Finance Sciences, Kharazmi University, Tehran, Iran. His research interests include private equity, venture capital, and contracting.

Mohammad Ali Rastegar is an Associate Professor of Industrial Engineering at Tarbiat Modares University, Tehran, Iran. His research interests include financial and banking risks modelling, algorithmic trading, asset-debt management, agent-based simulation, and investment management. He has published papers in some reputable journals such as Handbook of Power Systems II, Solar Energy, International Journal of Finance and Managerial Accounting, etc. 